\title{
Microsurgical Anatomy and Variations of the Anterior Clinoid Process
}

\section{Anterior Klinoid Proçes Mikrocerrabi Anatomisi ve Varyasyonları}

\author{
Ahmet DAGTEKIN ${ }^{1}$, Emel AVCI ${ }^{1}$, Denız UZMANSEL ${ }^{2}$, Zeliha KURTOGLU², Engin KARA ${ }^{3}$, Kutluay ULUC ${ }^{4}$, \\ Erinc AKTURE ${ }^{4}$, Mustafa K. BASKAYA ${ }^{4}$ \\ ${ }_{1}^{1}$ Mersin University, School of Medicine, Department of Neurosurgery, Mersin, Turkey \\ ${ }^{2}$ Mersin University, School of Medicine, Department of Anatomy, Mersin, Turkey \\ ${ }^{3}$ Mersin University, School of Medicine, Department of Radiology, Mersin, Turkey \\ ${ }^{4}$ University of Wisconsin, Department of Neurological Surgery, Madison, Wisconsin, USA
}

Presented in: 5th International Symposium on Microneurosurgical Anatomy, poster presentation, 4-6 November 2010, Istanbul, Turkey.

Corresponding Author: Mustafa K. BASKAYA / E-mail: m.baskaya@neurosurgery.wisc.edu

\begin{abstract}
AIM: The aim of this study was to better define the microsurgical anatomy of the supra/parasellar region and describe variations of the anterior clinoid process (ACP).

MATERIAL and METHODS: Fifteen formalin-fixed cadaver heads and 25 dry skulls were used to define the microsurgical anatomy of the ACP and related structures. The presence of the caroticoclinoid foramen (CaCF) as well as other relevant measurements were all noted. Radiological examination of the CaCF was also demonstrated on dry skulls.

RESULTS: Interosseous bridges, which form between the anterior and middle clinoid processes or connect all three (anterior, middle and posterior) clinoid processes, were found in $30 \%$ of the specimens. The average basal width, length and thickness of the ACP were $7.3 \mathrm{~mm}, 9.7$ $\mathrm{mm}$ and $5.4 \mathrm{~mm}$, respectively. Length of the optic nerve (ON) up to the falciform ligament (FL) was $10.9 \mathrm{~mm}$; length of the ON under the $\mathrm{FL}$ was $2.7 \mathrm{~mm}$; length of $\mathrm{ON}$ after removal of the ACP and unroofing the optic canal was $21.1 \mathrm{~mm}$.

CONCLUSION: This study contributes to the relationship of important vascular, neural, bone and dural layers of this region and also demonstrates the variations of ACP by means of microsurgical dissections and radiological examinations.
\end{abstract}

KEYWORDS: Anterior clinoid process, Microsurgical anatomy, Parasellar region, Suprasellar region, Variation

öz

AMAÇ: Sellar ve parasellar bölgenin mikrocerrahi anatomisinin daha iyi açıklanması ve anterior klinoid proçes varyasyonlarının belirlenmesi. YÖNTEM ve GEREÇLER: Formalin ile fikse edilmiş 15 kadavra, 25 kuru kafa kullanılmıştır. Karotikoklinoid foramen yüzdesi ve bu bölge ile ilgili ölçümler belirlenmiştir. Kuru kafalarda karotikoklinoid foramen radyolojik olarak gösterilmiştir.

BULGULAR: Interosseöz köprü, anterior ve orta klinoid proçes birleşmesiyle veya diğer 3 klinoid proçesin (anterior, orta, arka klinoid proçes) birleşmesiyle oluşur ve bu varyasyon $\% 30$ oranında tespit edilmiştir. Anterior klinoid proçesin bazal genişliği, uzunluğu ve kalınlığı sırası ile 7,3 $\mathrm{mm}, 9,7 \mathrm{~mm}$ ve 5,4 mm olarak bulunmuştur. Optik sinirin falsiform ligamana olan uzaklığı 10,9 mm, falsiform ligaman altındaki uzaklığı 2,7 mm, optik sinirin anterior klinoid proçes alındıktan ve optik kanal açıldıktan sonraki uzunluğu 21,1 mm olarak bulunmuştur.

SONUÇ: Çalışmada anterior klinoid proçes varyasyonları ve bu bölge ile ilgili önemli vasküler, nöral ve kemik yapıların ilişkisi mikrocerrahi ve radyolojik çalışma ile yeniden değerlendirilmiştir.

ANAHTAR SÖZCÜKLER: Anterior klinoid proçes, Mikrocerrahi anatomi, Parasellar bölge, Suprasellar bölge, Varyasyon

\section{INTRODUCTION}

Safe surgical exposure of the supra and parasellar region has become critically important for many lesions including jugum sphenoidale (planum sphenoidale), clinoidal and tuberculum sellae meningiomas, paraclinoidal aneurysms, and cavernous sinus tumors. The anatomical relationships of the ACP, $\mathrm{ON}$, chiasm, internal carotid artery (ICA), ophthalmic artery $(\mathrm{OA})$ and falciform ligament $(\mathrm{FL})$ are complex and represent important variations. In the past three decades a number of researchers have examined some parts of the supra- and parasellar region, yet the anatomy of this area remains complex and varied $(3,7,9-12,19,22-24,29,31,32,34,35)$. This region also is one of the most common that can be affected by many neoplastic and vascular neurosurgical lesions. Several skull base approaches (orbito-zygomatic, transbasal, cranio-orbital, pretemporal transzygomatic), conventional craniotomies (pterional, subfrontal) and endoscopic approaches have been 
performed to treat various lesions of this region. Detailed anatomical, clinical and radiological studies have been conducted, yet patients would benefit from a more in-depth understanding of the region. This study is designed to focus on the variations of the anterior clinoid process and define the microsurgical anatomy of the supra and parasellar region.

\section{MATERIAL and METHODS}

Fifteen fixed human cadaver heads were injected with colored silicone. A cranioorbital approach was performed bilaterally (30 sides). Microsurgical anatomical dissections and measurements were performed with a Leica, Wild M695 surgical microscope from $3 \mathrm{X}$ to $40 \mathrm{X}$ magnification at the Department of Neurological Surgery, University of Wisconsin-Madison. After the cranioorbital approach, anatomical relationship of the ACP with adjacent neurovascular structures, the position of the chiasm and the variations of the diaphragma sellae are observed. Measurements j (optic nerve length between chiasm to falciform ligament), $\mathrm{k}$ (optic nerve length under the falciform ligament), $m$ (length of internal carotid artery before removing the anterior clinoid process) are performed. After the dissections for intradural removal of the ACP and the division of the $F L$ and optic canal unroofing, the origin of the OA and its relationship with distal dural ring (DDR) are observed on cadaver heads. After clinoidectomy and unroofing of the optic canal, measurements I (length of optic nerve after the removal of anterior clinoid process and unroofing of the optic canal) and $\mathrm{n}$ (length of internal carotid artery after removing anterior clinoid process) and are performed. For the determination of the location of the ONs, the distance between the posterior end of the crista galli and the limbus sphenoidale (LS), which is the posterior border of the prechiasmatic sulcus (PS), is measured. The distance from LS to tuberculum sellae (TS) is also measured. In addition we examined the location of the chiasm according to the TS and dorsum sellae (DS).

In addition, measurements in the region of the ACP were also performed on 25 dry skulls ( 50 sides) with digital calipers at the Department of Neurological Surgery and Anatomy, University of Mersin-Turkey. The length of the ACP was measured from the level of the optic canal (OC) roof to the tip of the ACP in the dry skulls. The basal width of the ACP was measured from lateral margin of the optic foramen (OF) to lateral margin of the $A C P$; the thickness of the ACP was measured at its base. The dry skulls in which the CaCF was present were also examined with thin section axial and 3D computed tomography (CT) to better demonstrate these radiological variations at the Department of Radiology, University of Mersin-Turkey.

\section{RESULTS}

Bony Anatomical and Radiological Findings: The body of the sphenoidale bone consists of two parts: the anterior presphenoid portion and a posterior basisphenoid. The anterior presphenoid portion is in the anterior and middle cranial fossa, and the posterior basisphenoid bone constitutes the center of the middle cranial fossa. The posterior aspect of the presphenoid portion is formed from anterior to the posterior, the jugum sphenoidale (JS), limbus of sphenoid (LS), prechiasmatic sulcus and TS, respectively (Figure 1A,B). The LS is the posterior border of the JS. The sphenoidale bone also includes the hypophysial fossa, which is limited anteriorly
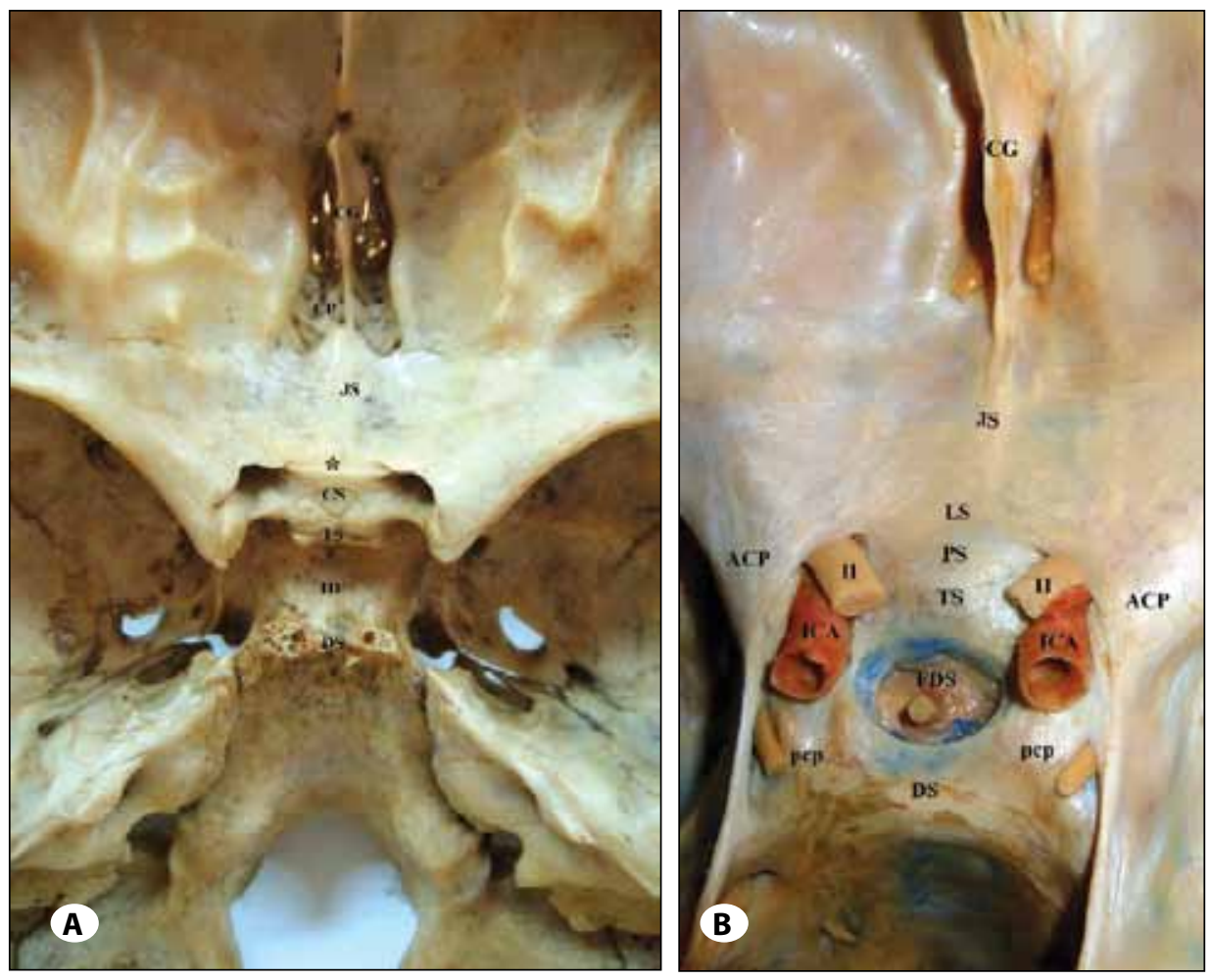

Figure 1: A) The internal surface of the anterior cranial fossa from above in the dry skull.

CG: Crista galli, CP: Cribriform plate,

JS: Jugum sphenoidale,

*: Limbus of sphenoid,

PS: Prechiasmatic sulcus,

TS: Tuberculum sellae,

HF: Hypophysial fossa,

DS: Dorsum sellae.

B) After the removal of the

brain, anterior cranial fossa and anterior clinoid region have been demonstrated.

CG: Crista galli, JS: Jugum sphenoidale, LS: Limbus of sphenoid, PS: Prechiasmatic sulcus, TS: Tuberculum sellae, DS: Dorsum sellae, FDS: Foramen diaphragma sellae, ACP: Anterior clinoid process, II: Optic nerve, ICA: Internal carotid artery, pcp: Posterior clinoid process. 
by the TS and posteriorly by the dorsum sellae DS. The TS is a slight bony prominence that separates the hypophysial fossa from the prechiasmatic sulcus which is located anterior to the TS and posterior to the LS. In the anterior cranial fossa the mean distance of the posterior border of the crista galli to the LS was found to be $2 \mathrm{~cm}$. The mean distance from the LS to the TS was measured as $6.7 \mathrm{~mm}$ (Table I, Figure 2).

The ACP is located at the medial end of the lesser wing of the sphenoidale bone. This bony projection is connected to the body of the sphenoidale bone by two roots. The superior root forms the roof of the OC and continues as the JS; the inferior root forms ventral and lateral walls of the OC. On its inferomedial aspect, the ACP is connected to the sphenoid body via the optic strut $(1,21)$. The length of the ACP was measured from the level of the OC roof to the tip of the ACP in the dry skulls. The basal width of the ACP was measured from lateral margin of the optic foramen (OF) to lateral margin of the ACP; the thickness of the ACP was measured at its base (Figure 2). All measurements performed in this region are shown in Table II.

The ACP is one of the most prominent bony processes of the parasellar region. The middle clinoid process $(\mathrm{MCP})$ is a small indeterminate bony projection which arises from the lateral surface of the body of the sphenoidale bone and medial side of the carotid sulcus. The CaCF is formed by the complete bony fusion between the ACP and the MCP and is located at the roof of the cavernous sinus (32). This was found in $15 \%$ of the dry specimens (Figure $3 \mathrm{~A}-\mathrm{C}$ ). Incomplete fusion results in

Table I: Sellar and Parasellar Region Measurements

\begin{tabular}{|c|c|c|}
\hline Parameters $(\mathbf{m m})$ & Range & Mean \\
\hline $\mathbf{a}(\mathbf{n}=\mathbf{2 5})$ & $19-29.3$ & 24.1 \\
\hline $\mathbf{b}(\mathbf{n}=\mathbf{2 5})$ & $8.9-16.7$ & 13 \\
\hline $\mathbf{c}(\mathbf{n}=\mathbf{2 5})$ & $17.2-23.6$ & 20 \\
\hline $\mathbf{d}(\mathbf{n}=\mathbf{2 5})$ & $3.5-11.5$ & 6.7 \\
\hline $\mathbf{e}(\mathbf{n}=\mathbf{1 5})$ & $16.3-19.5$ & 17.7 \\
\hline $\mathbf{f}(\mathbf{n}=\mathbf{1 5})$ & $8.3-11.9$ & 10.1 \\
\hline
\end{tabular}

a: Distance between anterior clinoid tips, b: Distance between posterior clinoid tips, c: Distance between posterior border of the crista galli to limbus sphenoidale, d: Distance between limbus sphenoidale to tuberculum sellae, e: Distance between optic nerve at the level of the falciform ligament, f: Distance between falciform ligament to the anterior border of the foramen diaphragma sellae. a bony bridge between the ACP and MCP, and this variation was found in $10 \%$ of the specimens. The posterior clinoid process (PCP) is situated at the superolateral corner of the dorsum sellae. An interclinoid bony fusion can occur between the ACP and the PCP, and this connection was found in $5 \%$ of the specimens (Figure $4 A-C$ ). It was also found in dry skulls whereby the caroticoclinoid foramen was present via axial and 3D CT.

Dural Fold, Vascular and Neural Anatomical Findings: The ACP and the FL obscure neurovascular structures in supra- and parasellar regions. The FL extends medially from the ACP across the ON, to the posterior border of the JS. This dural fold covers several millimeters of the $\mathrm{ON}$ before the proximal opening of the optic canal. Mean length of the ON from chiasm to the FL was found to be $10.9 \mathrm{~mm}$. The length of the ON was $2.7 \mathrm{~mm}$ under the FL (Figure 5A). After removal of the $A C P$ and unroofing the optic canal, the mean length of the $O N$ from the chiasm to the annulus Zinn was found to be $21.1 \mathrm{~mm}$

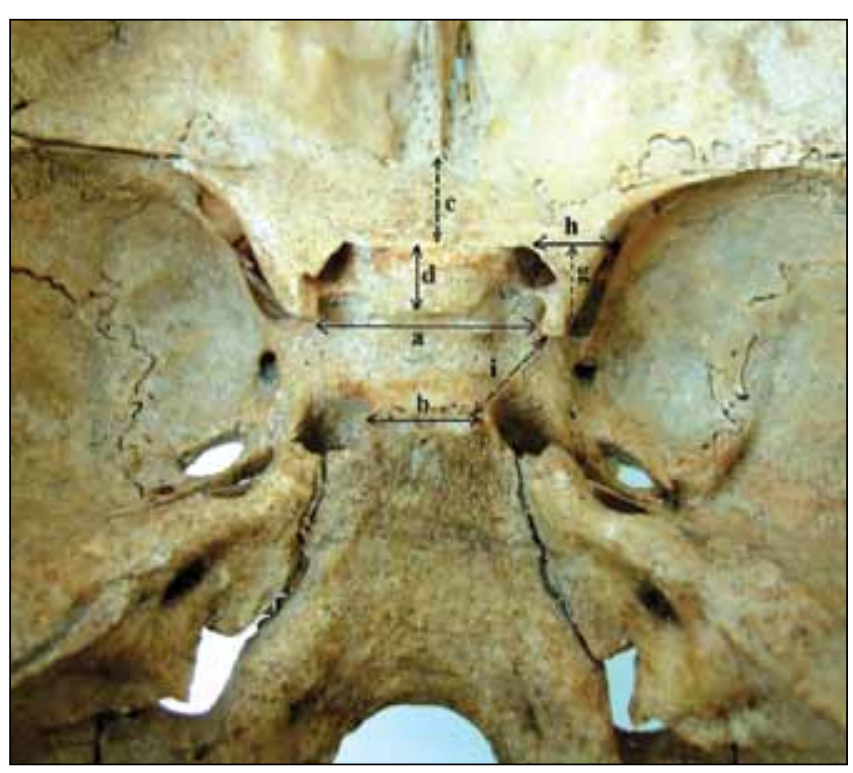

Figure 2: Anterior clinoid process region and anterior cranial base measurements have been shown. a- Distance between anterior clinoid tips, b- Distance between posterior clinoid tips, c- Distance between posterior border of the crista galli to limbus of sphenoid, d- Distance between limbus of sphenoid to tuberculum sellae, $\mathbf{g}$ - Length of the anterior clinoid process, h- Width of the anterior clinoid process, i- Anterior clinoid tip to the posterior clinoid tip.

Table II: ACP Measurements

\begin{tabular}{|c|c|c|c|c|}
\multirow{2}{*}{ Parameters $(\mathrm{mm})$} & \multicolumn{2}{|c|}{ Right $(\mathrm{n=25)}$} & \multicolumn{2}{c|}{ Left $(\mathrm{n=25})$} \\
\cline { 2 - 5 } $\mathbf{g}$ & Range & Mean & $6.3-11.8$ & 9.6 \\
h & $6.1-12.8$ & 9.7 & $5.3-10.5$ & 7.2 \\
i & $5.6-11.3$ & 7.3 & $0-10.3$ & 7.5 \\
ACP thickness & $0-10.8$ & 7.7 & $2.2-6.9$ & 5.3 \\
\hline
\end{tabular}

g: Length of the anterior clinoid process, $\boldsymbol{h}$ : Width the anterior clinoid process, i: Anterior clinoid tip to the posterior clinoid tip, ACP: Anterior clinoid process. 

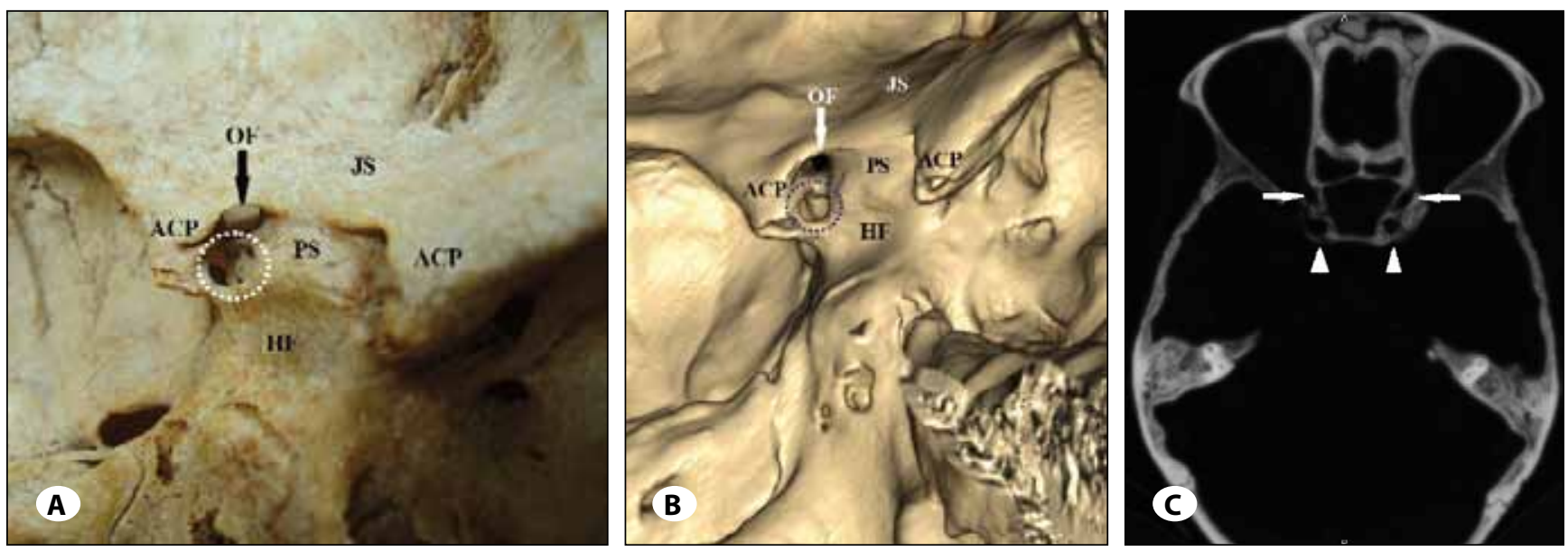

Figure 3: A) Caroticoclinoid foramen which has been formed between anterior and middle clinoid processes has been shown on a dry skull. ACP: Anterior clinoid process, JS: Jugum sphenoidale, PS: Prechiasmatic sulcus, HF: Hypophysial fossa, OF: Optic foramen. The caroticoclinoid foramen is circled with dotted line. B) Caroticoclinoid foramen has been demonstrated on 3D computed tomography. ACP: Anterior clinoid process, JS: Jugum sphenoidale, PS: Prechiasmatic sulcus, HF: Hypophysial fossa, OF: Optic foramen. The caroticoclinoid foramen is circled with dotted line. C) Caroticoclinoid foramina have been shown on thin sectioned computed tomography. White arrows point optic foramina. Arrowheads point caroticoclinoid foramina.
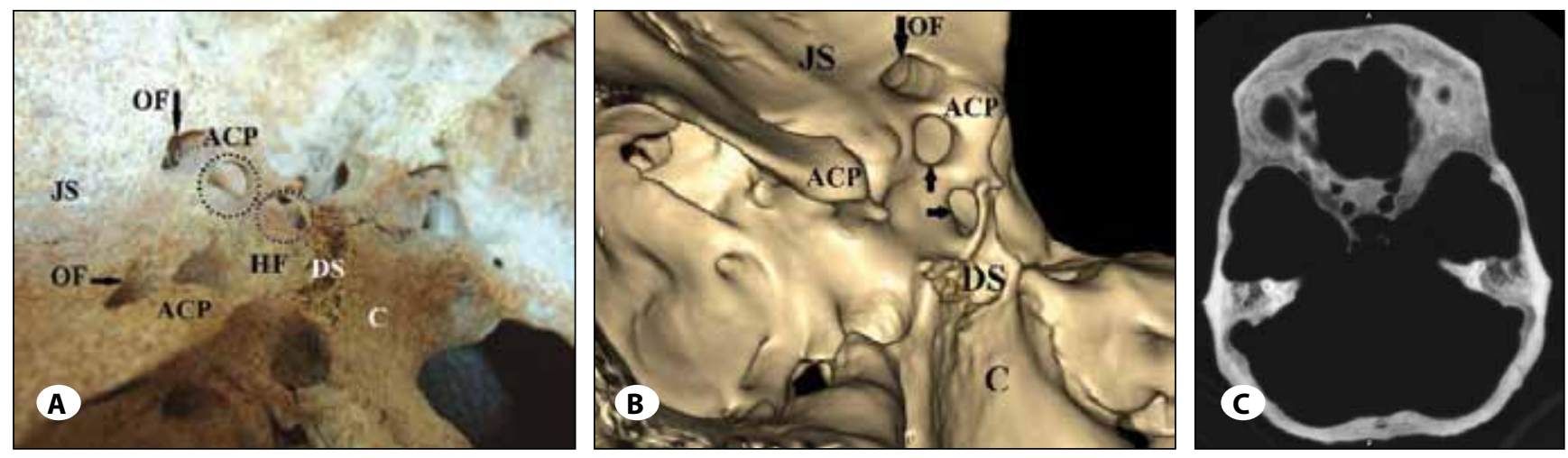

Figure 4: A) Caroticoclinoid foramina which have been formed between anterior, middle and posterior clinoid processes have been shown on a dry skull. ACP: Anterior clinoid process, JS: Jugum sphenoidale, HF: Hypophysial fossa, OF: Optic foramen, DS: Dorsum sellae, C: Clivus. Both caroticoclinoid foramina are circled with dotted lines. B) Caroticoclinoid foramina have been demonstrated on 3D computed tomography. ACP: Anterior clinoid process, JS: Jugum sphenoidale, OF: Optic foramen, DS: Dorsum sellae, C: Clivus, arrows were showing caroticoclinoid foramina. C) Caroticoclinoid foramina have been shown on thin sectioned computed tomography.
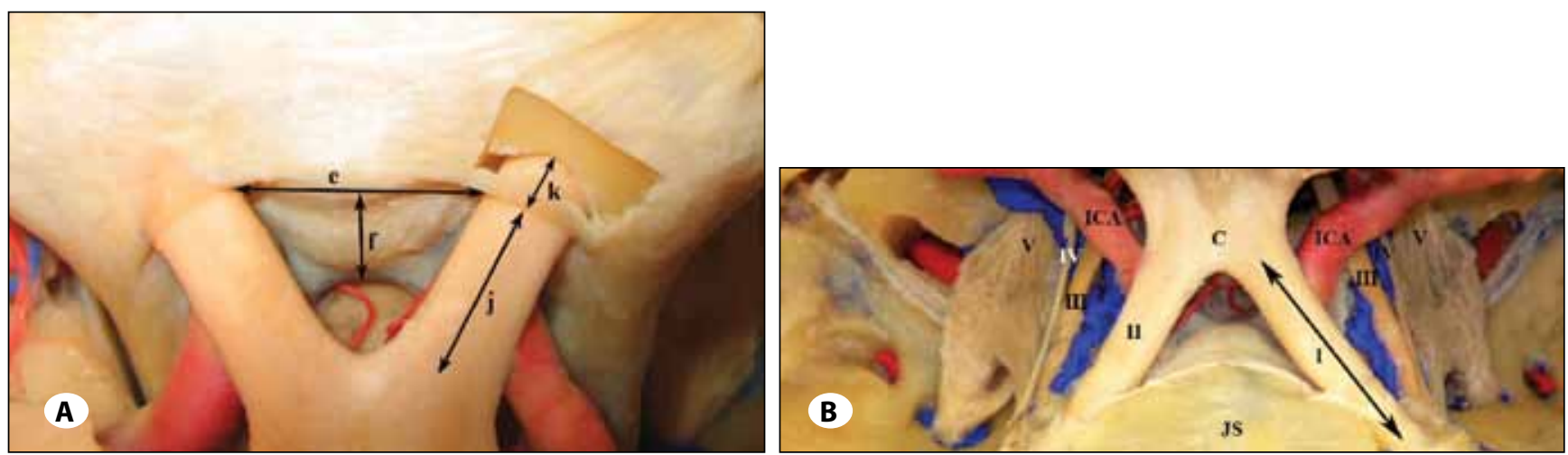

Figure 5: Different parts of the optic nerve measurements have been shown on cadavers. A) j- Optic nerve length from chiasm to falciform ligament, k- Optic nerve length under the falciform ligament, e- Distance between optic nerve at the level of the falciform ligament, $\mathbf{f}$ - Distance between falciform ligament to the anterior border of the foramen diaphragma sellae. B) I-Optic nerve length has been demonstrated after the removal of anterior clinoid process and unroofing of the optic canal. II: Optic nerve, ICA: Internal carotid artery, V: Trigeminal nerve, C: Chiasm, III: Oculomotor nerve, IV: Trochlear nerve, JS: Jugum sphenoidale. 
(Figure 5B). Removal of the ACP and optic unroofing along with excision of the FL resulted in an approximately two-fold increase of the exposure. The distance between ONs at the level of the FL was found to be $17.7 \mathrm{~mm}$.

The OA arises from the ICA at the level of the DDR with a mean of $2.3 \mathrm{~mm}$ (Figure $6 \mathrm{~A}, \mathrm{~B}$ ). In one specimen $(3.3 \%$ ) the $\mathrm{OA}$ originated from the clinoidal (C5) segment of the ICA, and in two specimens (6.6\%) at the level of the DDR. In these two specimens, the ring was attached to the OA. The OA was absent on the left side in one of the specimens (Figure $6 C$ ). The ICA from the most proximal visible point where it was uncovered by the ACP to the bifurcation before and removal of the ACP was also measured (Figure $7 A, B$ ). These results are shown in Table III.

The diaphragma sellae is a continuation of the dura mater covering the TS, the ACP, DS and PCP. The central opening of the diaphragma sellae is divided into open and closed types. The horizontal diameter of the central opening of the diaphragma sellae (foramen diaphragma sellae) was $\geq 5 \mathrm{~mm}$ in open type, and $<5 \mathrm{~mm}$ in closed type $(7,19)$. We found closed type foramen diaphragma sellae in two specimens $(13.3 \%)$ (Figure $8 \mathrm{~A}-\mathrm{B}$ ). The mean horizontal diameter of the foramen diaphragma sellae was $6.8 \mathrm{~mm}$ (Figure $8 \mathrm{C}$ ). The mean length of the anterior border of the foramen diaphragma sellae to the infindubulum was $5.6 \mathrm{~mm}$ (Figure $8 \mathrm{C}$ ). In addition, the diaphragma sellae was found to be thinner around the infindubulum and thicker at the periphery in every specimen.

The optic chiasm usually hangs directly over the hypophysial fossa. When it overlies the prechiasmatic sulcus or the TS it is called pre-fixed chiasm, whereas when it overlies the DS it is called post-fixed chiasm (32). In one of 15 cadaver heads, the chiasm was in a pre-fixed position (7\%) (Figure 9A); post-fixed chiasm was found in 7\% of the specimens (Figure 9B).
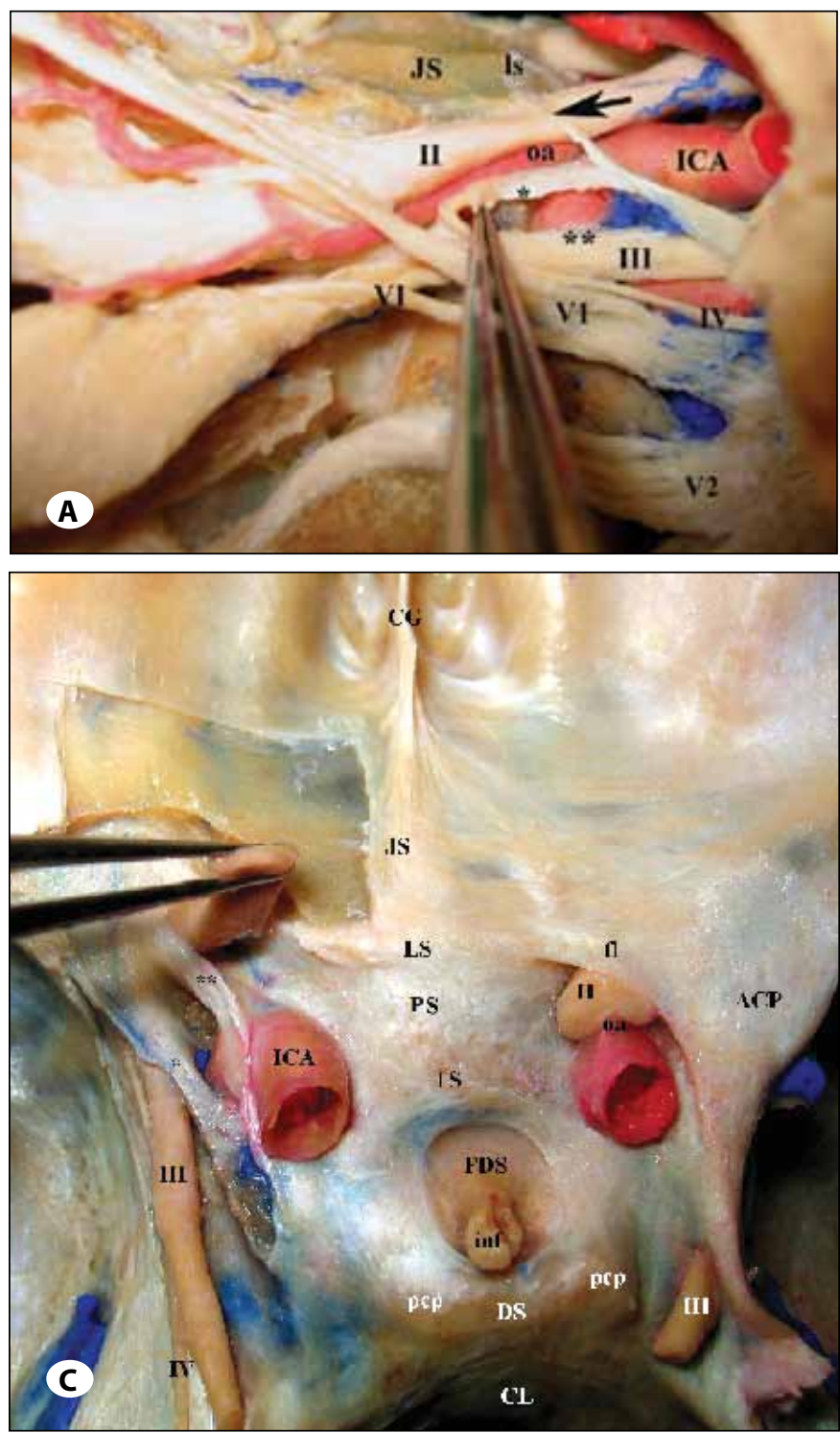

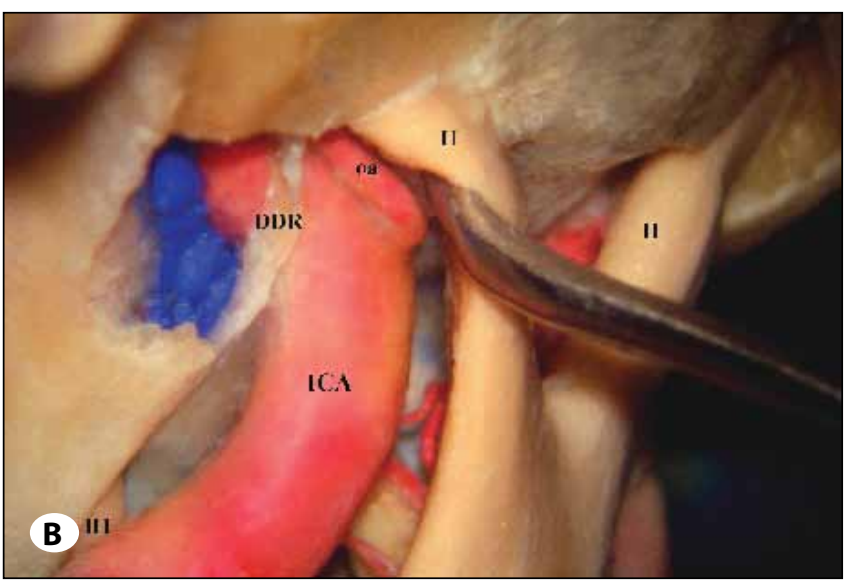

Figure 6: A) Localization of the ophthalmic artery has been demonstrated on cadaver. II: Optic nerve, Is: Limbus of sphenoid, JS: Jugum sphenoidale, III: Oculomotor nerve, IV: Trochlear nerve, ICA: Internal carotid artery, V1: First branch of the trigeminal nerve, V2: Second branch of the trigeminal nerve, oa: Ophtalmic artery, **: Proximal dural ring, VI: Abducens nerve, *: Distal dural ring. Arrow points the falciform ligament. B) Cranioorbital approach and intradural anterior clinoidectomy have been performed. Relationship of the ophthalmic artery and distal dural ring is shown. II: Optic nerve, oa: Ophtalmic artery, DDR: Distal dural ring, ICA: Internal carotid artery, III: Oculomotor nerve. C) Absence of the left ophthalmic artery has been demonstrated after the transposition of the left optic nerve. CG: Crista galli, JS: Jugum sphenoidale, LS: Limbus of sphenoid, PS: Prechiasmatic sulcus, TS: Tuberculum sellae, FDS: Foramen diaphragma sellae, DS: Dorsum sellae, ACP: Anterior clinoid process, pcp: Posterior clinoid process, CL: Clivus, inf: Infindubulum, II: Optic nerve, *: Proximal dural ring, **: Distal dural ring, fl: Falciform ligament, oa: Ophtalmic artery, III: Oculomotor nerve, IV: Trochlear nerve. 
Table III: Optic Nerve and Internal Carotid Artery Measurements

\begin{tabular}{c|c|c|c|c|}
\multirow{2}{*}{ Parameters $(\mathrm{mm})$} & \multicolumn{2}{|c|}{ Right $(\mathbf{n = 1 5 )}$} & \multicolumn{2}{c|}{ Left $(\mathbf{n = 1 5})$} \\
\cline { 2 - 5 } j & Range & Mean & $8-11.8$ & 10.9 \\
k & $8.2-11.9$ & 11 & $2.1-2.8$ & 2.5 \\
I & $2.3-3.3$ & 2.8 & $19-24$ & 21.1 \\
m & $19.1-23.8$ & 21 & $4.8-16$ & 11.8 \\
n & $6.5-14.7$ & 10.8 & $15.7-22.9$ & 19.2 \\
\end{tabular}

j: Optic nerve length between chiasm to falciform ligament, $\boldsymbol{k}$ : Optic nerve length under the falciform ligament, l: The length of optic nerve after the removal of anterior clinoid process and unroofing of the optic canal, $\mathbf{m}$ : Length of internal carotid artery before removing the anterior clinoid process, $\boldsymbol{n}$ : Length of internal carotid artery after removing anterior clinoid process.
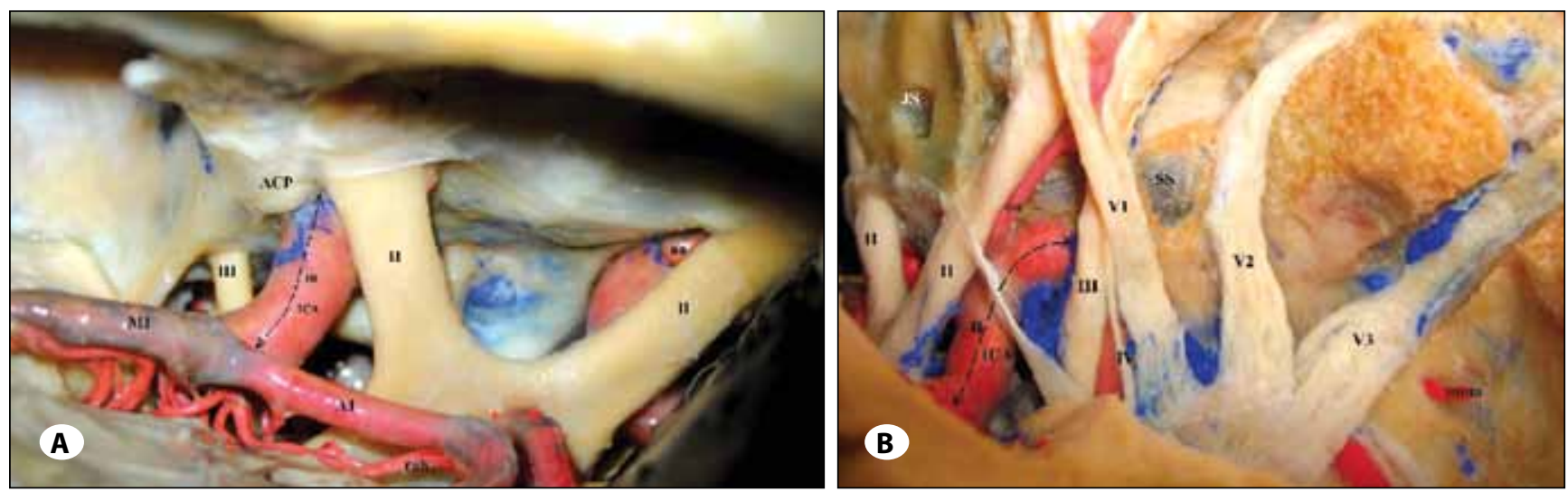

Figure 7: A) The length of internal carotid artery is shown fom the most proximal visible point where it is permitted by anterior clinoid process to the bifurcation. $\mathbf{m}$ : Length of ICA before removing the ACP, II: Optic nerve, ACP: Anterior clinoid process, ICA: Internal carotid artery, III: Oculomotor nerve, oa: Ophthalmic artery, A1: A1 segment of the anterior cerebral artery, rah: Recurrent artery of Heubner, M1: M1 segment of the middle cerebral artery. B) The length of internal carotid artery has been presented after removal of the anterior clinoid process. n: Length of ICA after removing ACP, III: Oculomotor nerve, IV:Trochlear nerve, ICA: Internal carotid artery, V1: First branch of the trigeminal nerve, II: Optic nerve, V2: Second branch of the trigeminal nerve, V3: Third branch of the trigeminal nerve, oa: Ophthalmic artery, mma: Middle meningeal artery, SS: Sphenoid sinus, JS: Jugum sphenoidale, PS: Prechiasmatic sulcus.
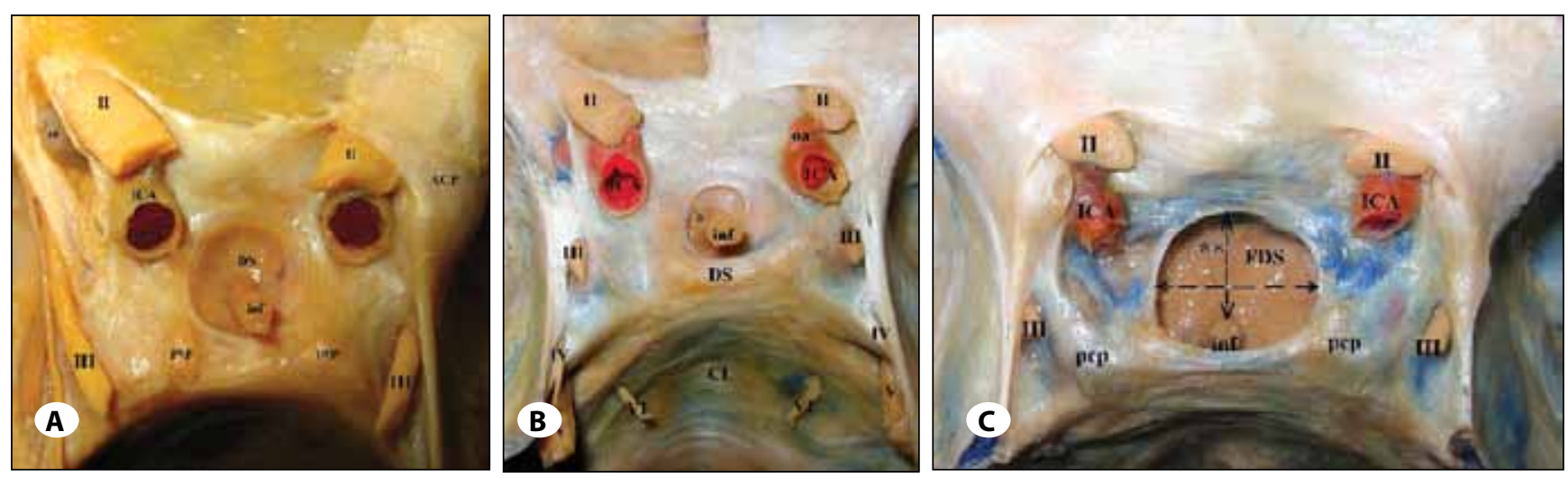

Figure 8: The diaphragma sellae is a circular dural fold and forms the roof of the hypophysial fossa. Types of diaphragma sellae demonstrated on cadaver heads. Closed type of diaphragma sellae has been shown in two specimens (A, B). A) Il: Optic nerve, ICA: Internal carotid artery, ss: Sphenoid sinus, ACP: Anterior clinoid process, pcp: Posterior clinoid process, inf: Infindubulum, DS: Diaphragma sellae, III: Oculomotor nerve, IV: Trochlear nerve. B) II: Optic nerve, oa: Ophtalmic artery, III: Oculomotor nerve, IV: Trochlear nerve, ICA: Internal carotid artery, V: Nervus trigeminus, VI: Abducens nerve, DS: Dorsum sellae, CL: Clivus, *: Diaphragma sellae, inf: Infindubulum. C) Open type of the diaphragma sellae has been shown. Diameter of the foramen diaphragma sellae and the distance between anterior border of the diaphragma sellae to infindubulum have been demonstrated. II: Optic nerve, ICA: Internal carotid artery, III: Oculomotor nerve, pcp: Posterior clinoid process, inf: Infindubulum, FDS: Foramen diaphragma sellae, ${ }^{* *}:$ The mean length of the anterior border of the foramen diaphragma sellae to the infindubulum is shown. 

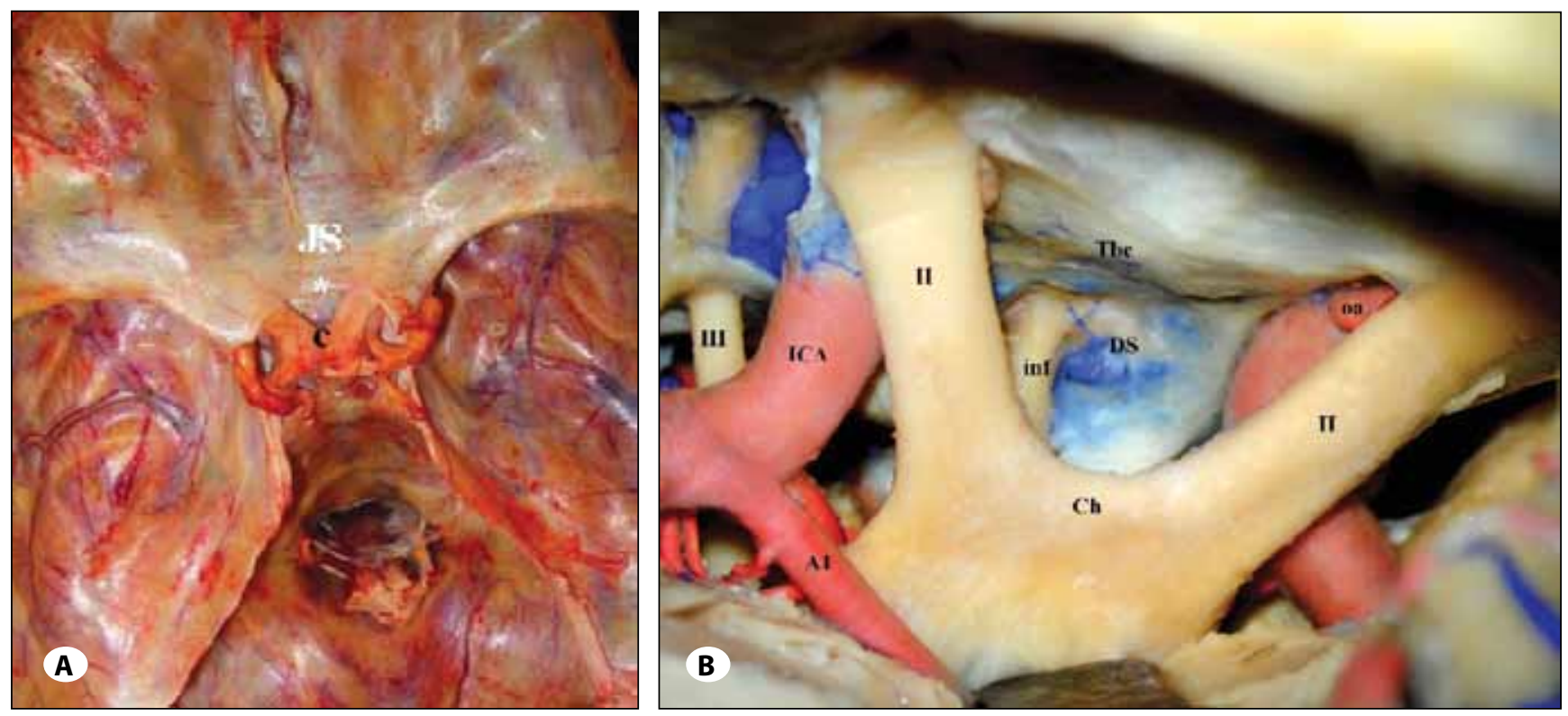

Figure 9: Anatomical variations of the chiasm localizations have been shown. A) Pre-fixed chiasm in which the chiasm overlies the prechiasmatic sulcus or tuberculum sellae. JS: Jugum sphenoidale, *: Limbus of sphenoid, c: Chiasm. B) Post-fixed chiasm in which the chiasm overlies the dorsum sellae. DS: Diaphragma sellae, III: Oculomotor nerve, II: Optic nerve, ICA: Internal carotid artery, oa: Ophtalmic artery, Tbc: Tuberculum sellae, A1: Anterior cerebral artery A1 segment, ch: Chiasm, inf: Infindubulum.

\section{DISCUSSION}

Safe surgical resection via adequate surgical exposure is very critical in lesions involving the supra/parasellar region. There are several conventional (pterional, frontal) and skull base approaches (cranio-orbital, orbito-zygomatic) which are commonly used to access this region. Regardless of the location of the lesion or the surgical approach used, prominent bony structures pose difficulties for safe exposure by obscuring direct visualization of important neurovascular structures (midline sellar/suprasellar versus parasellar or clinoidal) in this region.

Of these bony prominences, the ACP is by far the most important bony projection which hides part of the $\mathrm{ON}$ and the ICA (Figure 10A, B). In the present study the average basal width, length and thickness of the ACP were found to be 7.3 $\mathrm{mm}, 9.7 \mathrm{~mm}$, and $5.4 \mathrm{~mm}$, respectively. Similar observations were reported by Gupta et al., Hunnargi et al., Huynh-Le et al., Lee et al., and in Nepal, Indian, Japan and Korean skulls, respectively $(15,16,20,28)$. The comparison of the findings revealed that the mean length of ACP is the longest in the Indian population. The comparison of our findings with the mentioned studies showed that the mean basal width is the shortest in Turkish population. The studies on the anatomy of the skull base, in different regions of the world, contribute to the knowledge suggesting that the age, gender, race, geographical distribution, genetic factors and socioeconomic status of the population play substantial role on the morphometry $(8,30)$. The ACP is the medial and posterior end of the lesser wing of the sphenoidale bone. An interclinoid bridge can form incomplete or complete CaCF between the
ACP and MCP or between the ACP and both MCP and PCP. During the removal of the ACP or $P C P$, extreme care should be exercised to preserve vital structures such as the $O N$, oculomotor nerve, ICA and OA. Thorough knowledge and awareness of the variations of the ACP and presence of the $\mathrm{CaCF}$ are crucial when performing surgeries in this region and prevent any unnecessary injury to neurovascular structures in their vicinity. In a study performed on human cadavers, Kim et al found complete bony fusion between the ACP and MCP in $13 \%$ of specimens studied, and an incomplete fusion in $24 \%$ of the specimens (21). They also demonstrated an interclinoid osseous bridge between the ACP and PCP in $6 \%$ of the specimens (33). We found an incomplete bony fusion between the ACP and MCP in $10 \%$ of specimens and a complete bony fusion ( $\mathrm{CaCF}$ ) in $15 \%$ of specimens. $A$ bony bridge between the ACP and PCP was found in $5 \%$ of the specimens.

Awareness of this variation is of great importance during drilling of the ACP or PCP, particularly in the presence of $\mathrm{CaCF}$ as it may result in vascular or neural injury by inadvertent fracture of this osseous bridge. The ACP is composed of a thin shell of outer cortical bone surrounding inner spongy bone. In a previous study, pneumatization of the right and left ACP were found in $12 \%$ and $7 \%$ of the scans, respectively. Bilateral pneumatization was found in $9 \%$ of cases, and a normal ACP was found in $72 \%$ of the scans (4). In order to prevent catastrophic complications, the dimensions and configuration of the ACP should be evaluated by thin section CT scan in those cases where ACP drilling is planned (26).

In order to determine the location of the ONs we measured the distance between the posterior end of the crista galli 

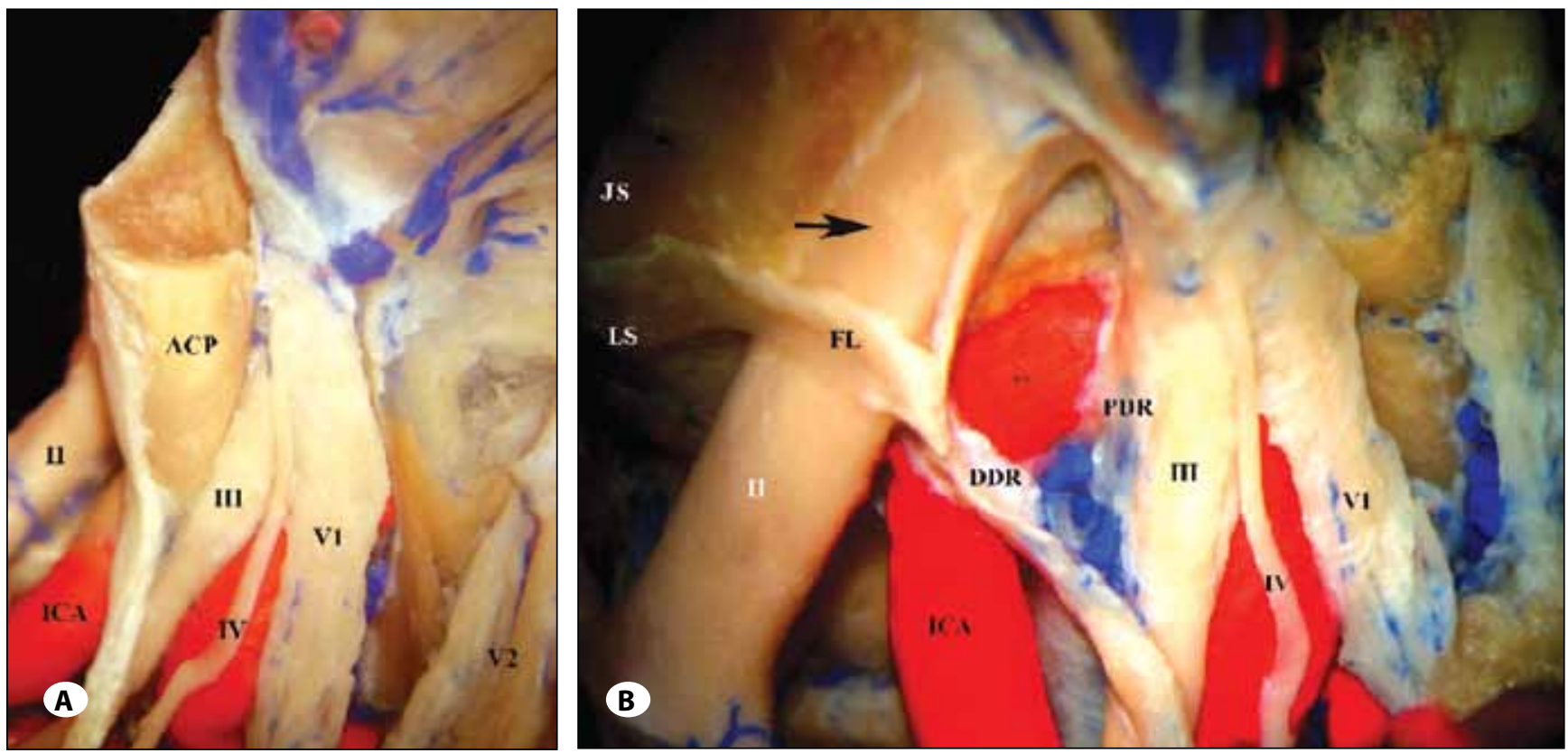

Figure 10: A) Anterior clinoid region has been demonstrated before removing the anterior clinoid process. II: Optic nerve, III: Oculomotor nerve, IV: Trochlear nerve, V1: First branch of the trigeminal nerve, V2: Second branch of the trigeminal nerve, ACP: Anterior clinoid process, ICA: Internal carotid artery. B) Removing the anterior clinoid process and unroofing of the optic canal have been performed and vital structures of this region have been demonstrated. V1: First branch of the trigeminal nerve, DDR: Distal dural ring, PDR: Proximal dural ring, JS: Jugum sphenoidale, LS: Limbus of sphenoid, II: Optic nerve, ICA: Internal carotid artery, III: Oculomotor nerve, IV: Trochlear nerve, ${ }^{* *}$ : Internal carotid artery clinoidal segment, FL: Falciform ligament. Black arrow shows the optic nerve after unroofing the optic canal.

and the LS, which is the posterior border of the JS. The mean distance was found to be $20 \pm 1.96 \mathrm{~mm}$ in 15 cadaver heads. While this distance was relatively constant, the distance from LS to TS showed a great variability (3.5 to $11.5 \mathrm{~mm}, 6.7 \pm 1.92$ $\mathrm{mm})$.

The dura that extends medially off the upper surface of the ACP forms the DDR (upper dural ring, fibrous ring, Perneczky's ring, and the true dural ring) around the ICA. The proximal dural ring (PDR) separates the $C 5$ segment of the ICA from the oculomotor nerve (6). Unlike the PDR, DDR forms a complete ring around and fuses with the adventitia of the ICA. The DDR is firmly adherent to the dorsolateral aspect of this vessel. Hence, blunt dissection of the DDR can lead to the tearing of the adventitia of the ICA $(4,25)$. The C5 segment of the ICA extends from the PDR to the DDR and lies immediately below the ACP. The DDR is a landmark for the end of the C5 segment and the beginning of the ophthalmic (C6) segment (Figure 11) (19). The PDR loosely surrounds the ICA. This anatomical condition allows extension of the cavernous venous channel around the clinoid ICA; the venous channel has been named the clinoid venous plexus which may have variable size (25). Our findings are in concordance with a study by Seoane et al (Figure 12) (33). The origin of the OA is an important anatomical condition. Our study demonstrated that one OA originated from the $\mathrm{C} 5$ segment (3\%), two originated at the level of the dural ring (6\%), and in one specimen there was no OA on the left side (3\%) (Figure 6C).
Removal of the ACP, incision of the FL and unroofing the optic canal are the most crucial maneuvers during surgery for many supra/parasellar tumors and paraclinoid aneurysms $(1,2,5,13,14,17,18,25)$. The FL covers several millimeters of the ON just proximal to the optic canal. In this study the ON extended freely under falciform ligament $2.7 \mathrm{~mm}$. Incision of the FL provides safe mobilization of the $\mathrm{ON}$ and exposes the $O A$. We demonstrated that removal of $A C P$, unroofing of the optic canal and sectioning the $\mathrm{FL}$ results in additional exposure of the $\mathrm{ON}$ with the mean value of $12 \pm 2 \mathrm{~mm}$.

The importance of drilling of the ACP and optic unroofing in resection of the tuberculum, diaphragma sellae meningiomas has been emphasized by Al-Mefty et al. and others $(1,2,5,14,25,27)$. Our results agree with these findings and support the idea of having the widest exposure in this region by excising the $F L$, drilling the $A C P$, and performing optic unroofing. In our experience, almost all of symptomatic tuberculum/diaphragma sellae meningiomas causing symptoms extend into the optic canal in varying degrees. Therefore, extensive drilling of the ACP and optic unroofing along with excision of the FL not only provide the widest exposure, mobilization of the $\mathrm{ON}$ and resection of the tumor parts extending into the optic canal, it may also allow resection of the involved dura to some extent. Although this is not the case in most of JS meningiomas, large and extensive ones may extend into the optic canal and may necessitate drilling of the ACP and optic unroofing (Figure 11). 


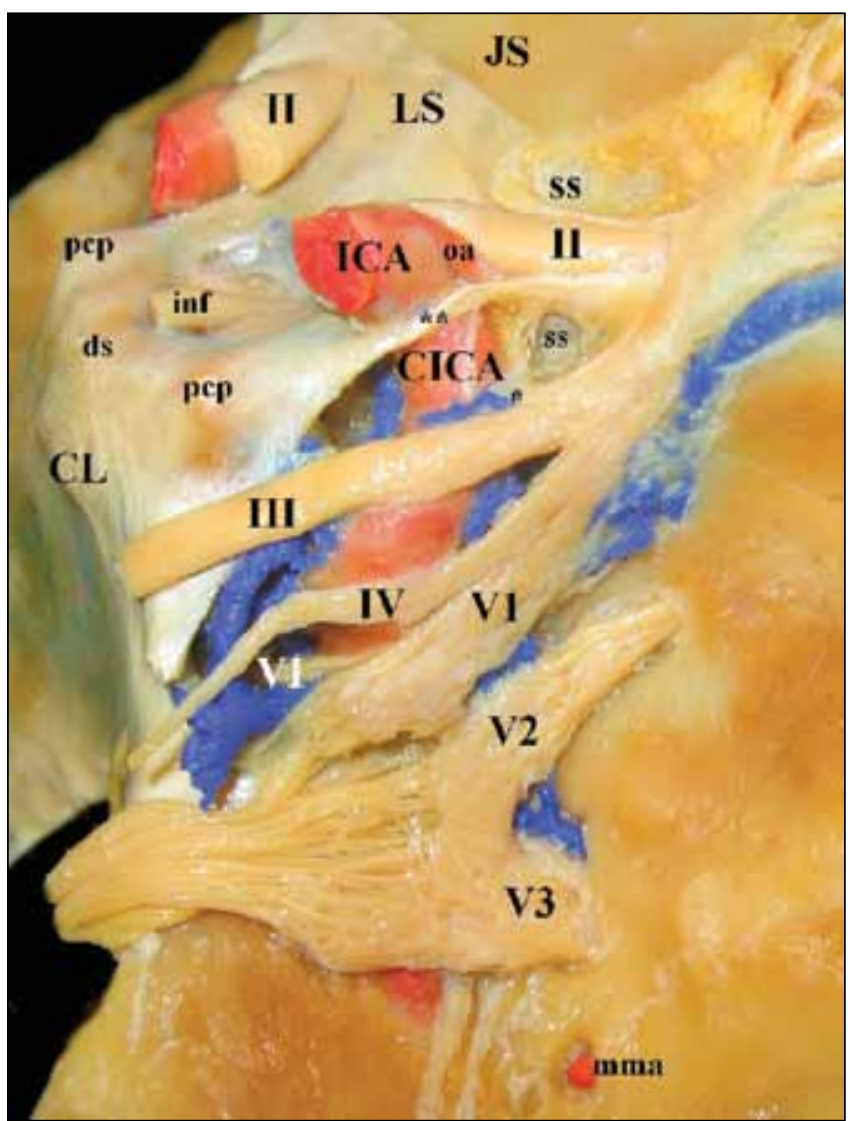

Figure 11: Anterior clinoid region, clinoidal internal carotid artery and dural rings have been dissected on the right side of cadaver head. II: Optic nerve, ICA: Internal carotid artery, V1: First branch of the trigeminal nerve, III: Oculomotor nerve, IV: Trochlear nerve, V2: Second branch of the trigeminal nerve, V3: Third branch of the trigeminal nerve VI: Abducens nerve, LS: Limbus of sphenoid, oa: Ophtalmic artery, *: Proximal dural ring, **: Distal dural ring, pcp: Posterior clinoid process, inf: Infindubulum, JS: Jugum sphenoidale, ds: Dorsum sellae, mma: Middle meningeal artery, ss: Sphenoid sinus, CICA: Internal carotid artery clinoidal segment, CL: Clivus.

The location of the optic chiasm relative to the structures underneath is of vital importance in the surgical removal of the sellar lesions such as pituitary adenomas and craniopharyngiomas. The pre-fixed chiasm can limit the access to the sellar lesions considerably. In this study, the chiasm was found to be pre-fixed in $7 \%$ of the specimens and post-fixed in $7 \%$ of the specimens.

\section{CONCLUSION}

The ACP and FL are bony and dural structures which obscure the supraclinoid ICA and the ON, and thus pose a significant challenge for safe exposure of this region. Variations and practical measurements provided by the present study may help clinicians to better understand the regional anatomy pertinent to neurosurgical procedures, as well as increase their likelihood of avoiding serious complications.

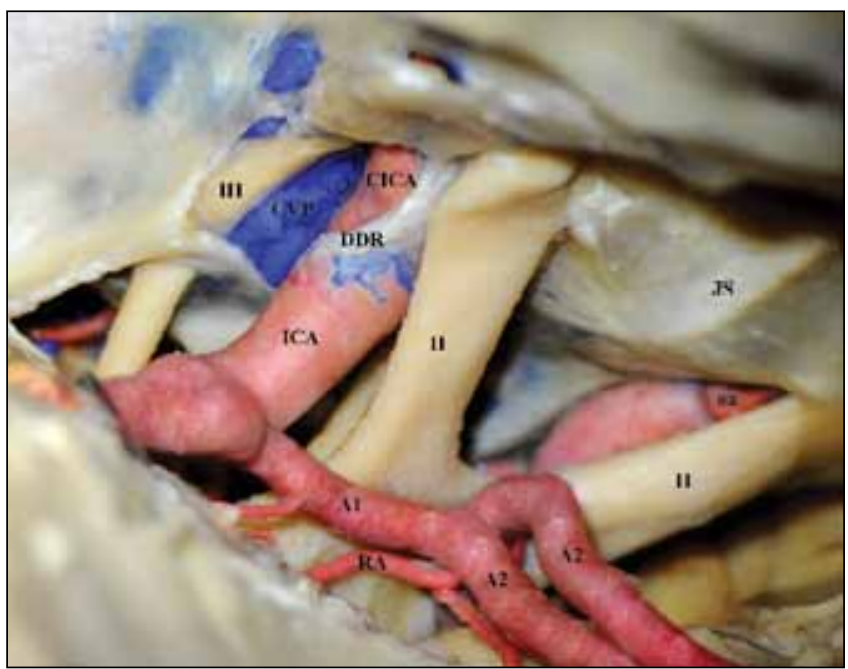

Figure 12: Clinoidal venous plexus has been shown on left side of cadaver head. II: Optic nerve, ICA: Internal carotid artery, III: Oculomotor nerve, CVP: Clinoidal venous plexus, JS: Jugum sphenoidale, CICA: Clinoidal internal carotid artery, DDR: Distal dural ring, oa: Ophtalmic artery, A1: A1 segment of the anterior cerebral artery, A2: A2 segment of the anterior cerebral artery, RA: Recurrent artery of Heubner.

\section{REFERENCES}

1. Al-Mefty O: Operative Atlas of Meningiomas. Philadelphia: Lippincott-Raven, 1998

2. Al-Mefty O, Smith RR: Tuberculum sellae meningiomas. In Al-Mefty O (ed), Meningiomas. New York:Raven Pres, 1991: 395-411

3. Andaluz N, Beretta F, Bernucci C, Keller JT, Zuccarello M: Evidence for the improved exposure of the ophthalmic segment of the internal carotid artery after anterior clinoidectomy: Morphometric analysis. Acta Neurochir 148: 971-975, 2006

4. Avci E, Bademci G, Öztürk A: Microsurgical landmarks for safe removal of anterior clinoid process. Minim Invasive Neurosurg 48: 268-272, 2005

5. Benjamin V, Russell SM: The microsurgical nuances of resecting tuberculum sellae meningiomas. Neurosurgery 56 Suppl 2: 411-417, 2005

6. Bouthillier A, van Loveren HR, Keller JT: Segments of the internal carotid artery: A new classification. Neurosurgery 38: 425-433, 1996

7. Campero A, Martins C, Yasuda A, Rhoton AL Jr: Microsurgical anatomy of the diaphragma sellae and its role in directing the pattern of growth of pituitary adenomas. Neurosurgery 62 : 717-723, 2008

8. Cheverud JM: Phenotypic, genetic and environmental integration in the cranium. Evolution 36: 499-516, 1982

9. Collignon F, Link M: Paraclinoid and cavernous sinus regions: Measurement of critical structures relevant for surgical procedure. Clin Anat 18: 3-9, 2005 
10. Dolenc VV: Approaches to and techniques of surgery within the cavernous sinus. In: Torrens M, Al-Mefty O, Kobayashi S (ed), Operative Skull Base Surgery. New York: Churchill Livingstone, 1997:207-236

11. Dolenc VV: A combined transorbital-transclinoid and transsylvian approach to carotid-ophthalmic aneurysms without retraction of the brain. Acta Neurochir Suppl 72: 89-97, 1999

12. Dolenc VV: Parasellar compartment. J Neurosurg 113: 1043-1044, 2010

13. Figueiredo EG, Tavares WM, Rhoton AL Jr, De Oliveira E: Surgical nuances of giant paraclinoid aneurysms. Neurosurg Rev 33: 27-36, 2010

14. Goel A, Muzumdar D, Desai Kl: Tuberculum sellae meningioma: A report on management on the basis of a surgical experience with 70 patients. Neurosurgery 51: 1358-1364, 2002

15. Gupta N, Ray B, Ghosh S: A study on anterior clinoid process and optic strut with emphasis on variations of caroticoclinoid foramen. Nepal Med Coll J 7(2): 141-144, 2005

16. Hayashi N, Masuoka T, Tomita T, Sato H, Ohtani O, Endo S: Surgical anatomy and efficient modification of procedures for selective extradural anterior clinoidectomy. Minim Invasive Neurosurg 47: 355-358, 2004

17. Heros RC: Paraclinoid aneurysms. J Neurosurg 96:647-648, 2002

18. Heros RC: Anterior paraclinoid aneurysms. J Neurosurg 96: 981-982, 2002

19. Hunnargi S, Ray B, Pai SR, Siddaraju KS: Metrical and nonmetrical study of anterior clinoid process in South Indian adult skulls. Surg Radiol Anat 30: 423-428, 2008

20. Huynh-Le P, Natori Y, Sasaki T: Surgical anatomy of the anterior clinoid process. Journal of Clinical Neuroscience 11(3):283287,2004

21. Inoue T, Rhoton AL Jr, Theele D, Barry ME: Surgical approaches to the cavernous sinus: A microsurgical study. Neurosurgery 26: 903-932, 1990

22. Isolan GR, de Aguiar PH, Laws ER, Strapasson AC, Piltcher $O$ : The implications of microsurgical anatomy for surgical approaches to the sellar region. Pituitary 12: 360-367, 2009
23. Ju KS, Bae HG, Park HK, Chang JC, Choi SK, Sim KB: Morphometric study of the korean adult pituitary glands and the diaphragma sellae. J Korean Neurosurg Soc 47:42-47, 2010

24. Kim JM, Romano A, Sanan A, van Loveren HR, Keller JT: Microsurgical anatomic features and nomenclature of the paraclinoid region. Neurosurgery 46:670-680, 2000

25. Kinjo T, Al-Mefty O, Ciric I: Diaphragma sellae meningiomas. Neurosurgery 36:1082-1092, 1995

26. Korosue K, Heros RC: "Subclinoid" carotid aneurysm with erosion of the anterior clinoid process and fatal intraoperative rupture. Neurosurgery 31:356-359, 1992

27. Lang J: Skull base and related structures. Atlas of Clinical anatomy. Stuttgart, New York: Schattauer, 1995

28. Lee HY, Chung IH, Choi BY, Lee KS: Anterior clinoid process and optic strut in Koreans. Yonsei Med J 38(3): 151-154, 1997

29. Mahmoud M, Nader R, Al-Mefty O: Optic canal involvement in tuberculum sellae meningiomas: Influence on approach, recurrence, and visual recovery. Neurosurgery 67 (3 Suppl operative): ons108-118, 2010

30. Ng MY, Sham PC,Paterson AD, Chan V, Kung AW: Effect of environmental factors and gender on the heritability of bone mineral density and bone size. Ann Hum Genet 70:428-438, 2006

31. Peker S, Kurtkaya Yapicier O, Kiliç T, Pamir MN: Microsurgical anatomy of the lateral walls of the pituitary fossa. Acta Neurochir 147: 641-648, 2005

32. Renn WH, Rhoton AL Jr: Microsurgical anatomy of the sellar region. J Neurosurg 43: 288-298, 1975

33. Seoane E, Rhoton AL Jr, de Oliveira E: Microsurgical anatomy of the dural collar (carotid collor) and rings around the clinoid segment of the carotid artery. Neurosurgery 42:869-884, 1998

34. Yang J, Wu X, Liu JX, Lin RS, Li ZQ, Ma SC, Qi JF, Cun EH, Yu $\mathrm{CJ}$ : Microanatomic and three-dimensional reconstruction study of lateral wall and related structures of optic canal. Zhonghua Yi Xue Za Zhi 91(5): 322-326, 2011

35. Yasuda A, Campero A, Martins C, Rhoton AL Jr, Ribas GC: The medial wall of the cavernous sinus: Microsurgical anatomy. Neurosurgery 55: 179-189, 2004 